Review

\title{
The Bright and Dark Side of Eudaimonic Emotions: A Conceptual Framework
}

\author{
Helen Landmann \\ Department of Community Psychology, FernUniversität in Hagen, 58084 Hagen, Germany; \\ E-Mail: helen.landmann@fernuni-hagen.de
}

Submitted: 7 November 2020 | Accepted: 8 March 2021 | Published: 6 May 2021

\begin{abstract}
Based on a review of eudaimonic emotion concepts, definitional and empirical overlaps between the concepts are identified and a framework of eudaimonic emotions is developed. The framework proposes that feelings of elevation, awe, tenderness, and being moved can be differentiated based on their feeling components, thus constituting the feeling-specific types of eudaimonic emotions. A variety of other emotion concepts rely on reference to their elicitors, such as moral elevation (i.e., being moved by moral virtue), aesthetic awe (i.e., being moved by beauty), kama muta (i.e., being moved by communal sharing) and admiration (i.e., being moved by achievements), thus constituting elicitor-specific types of eudaimonic emotions. Structuring eudaimonic emotions along these lines allows for integrating research on these emotions. This integration leads to the proposition of general eudaimonic effects and value-specific effects of positive eudaimonic emotions on behaviour. Considering these effects can enhance understanding of how positive eudaimonic emotions affect pro-social intentions - the bright side of being moved-as well as the manipulating effects of propaganda-the dark side of being moved.
\end{abstract}

\section{Keywords}

admiration; appreciation; awe; being moved; elevation; propaganda; tenderness

\section{Issue}

This review is part of the issue "The Good, the Bad, and the Ugly: Inspirational Media between Meaning, Narration, and Manipulation" edited by Lena Frischlich (University of Muenster, Germany), Diana Rieger (LMU Munich, Germany) and Lindsay Hahn (University at Buffalo-State University of New York, USA).

(C) 2021 by the author; licensee Cogitatio (Lisbon, Portugal). This review is licensed under a Creative Commons Attribution 4.0 International License (CC BY).

\section{Introduction}

People sometimes watch movies because they make them laugh or engage with social media because it is pleasurable. Communication research refers to these processes as hedonic motivations, which have served as a primary explanation for media use for decades (Oliver, 2008). However, hedonic motivations cannot explain why people watch movies that make them cry or search for online videos that are meaningful but not pleasurable to see. More recent research explains these phenomena via eudaimonic motivation: Striving for "greater insight, self-reflection, or contemplations of poignancy or meaningfulness (e.g., what makes life valuable)" (Oliver, 2008, p. 42). Recent research reveals that eudaimonic themes are prevalent not only in movies and
Facebook posts (Dale et al., 2020; Dale, Raney, Janicke, Sanders, \& Oliver, 2017) as well as digital games (Daneels, Bowman, Possler, \& Mekler, 2021), but also in extremist propaganda (Frischlich, 2020; Frischlich, Rieger, Morten, \& Bente, 2018). Accordingly, responses to these eudaimonic themes are relevant for the motivation to enhance others' well-being (Freeman, Aquino, \& McFerran, 2009) but also for attraction to extremist groups (Frischlich et al., 2018). Hence, eudaimonic motivations seem to have a bright side (i.e., enhancing others' well-being) but also a dark side (i.e., contributing to radicalization).

Emotional responses to eudaimonic themes are key for understanding eudaimonic motivation because affective responses to media motivate its consumption (Oliver et al., 2018). However, scholars have proposed a variety of different concepts addressing emotional reactions to 
eudaimonic content such as elevation, awe, kama muta, admiration, appreciation, being moved and tenderness. The extant literature on these eudaimonic emotions is somehow dissatisfactory because it typically focuses on one of these concepts while ignoring the literature on the respective other concepts. Attempts to compare or integrate the types of eudaimonic emotions consider only a subset of the relevant concepts (e.g., Algoe \& Haidt, 2009; Konečni, 2005; Shiota et al., 2017; Stellar et al., 2017; Tong \& Jia, 2017; Weidman \& Tracy, 2020; Yih, Kirby, \& Smith, 2020). However, an integration of eudaimonic emotions is strongly needed: As outlined below, the concepts largely overlap. For instance, most of them are experienced as 'moving' suggesting that the way these emotions are experienced overlap. Ignoring this overlap is highly inefficient because it means that progress in one line of research is not transferred to the others. Furthermore, research on the consequences of the different eudaimonic emotions point in different directions: For instance, research on elevation focuses on pro-social effects whereas research on admiration focuses on achievement-related effects. Hence, an integration of these concepts potentially clarifies their consequences for behaviour. The present manuscript is an attempt to disentangle the concepts and approaches on eudaimonic emotions. Based on a review of eudaimonic emotion concepts, a general framework of eudaimonic emotions is proposed that differentiates between feeling-specific and elicitor-specific emotions. This integration provides a basis for explaining the effects of eudaimonic emotions on pro- and anti-social intentions in the context of media use.

\section{Conceptualizations of Eudaimonic Emotions}

Drawing upon the aforementioned distinction between eudaimonic and hedonic motivation (Oliver, 2008), eudaimonic emotions can be defined as positive affective reactions to human virtues (e.g., moral and intellectual virtues), while hedonic emotions refer to positive affective reactions to self-focused short-term goals (e.g., pleasure). In line with this distinction, experimental studies show that humorous stimuli elicit amusement, whereas eudaimonic stimuli (e.g., close relationships, helping behaviour, or exceptional achievements) elicit feelings of being moved and touched (Landmann, Cova, \& Hess, 2019; Oliver et al., 2015; Schnall, Roper, \& Fessler, 2010). Eudaimonic emotions have been studied in emotion research (e.g., Menninghaus et al., 2015), philosophy (e.g., Cova \& Deonna, 2014) as well as in media and communication studies (e.g., Oliver \& Bartsch, 2010). However, scholars do not agree on a single conceptualization of eudaimonic emotions (Oliver et al., 2018). A variety of different concepts have been proposed to explain why and when people are moved, touched, and elevated. The most influential of these concepts are moral elevation, awe, kama muta, admiration, appreciation, being moved, and tenderness.

\subsection{Moral Elevation}

Moral elevation is defined as "a warm, uplifting feeling that people experience when they see unexpected acts of human goodness, kindness, and compassion" (Haidt, 2000, p. 1). Hence, moral elevation is defined by its feeling component (i.e., warm and uplifting) and its eliciting situation (i.e., witnessing human goodness). Characteristic items to assess moral elevation are 'uplifted,' 'moved,' 'touched,' 'respect,' 'inspired,' and 'awe' (Thomson \& Siegel, 2017). Moreover, episodes of moral elevation are associated with self-reported warm feelings in the chest, with 'tingling' feelings and with a desire to be a better person (Thomson \& Siegel, 2017). Moral elevation can be induced through movies (Oliver, Hartmann, \& Woolley, 2012; Waddell, Bailey, \& Davis, 2017), online videos (Krämer et al., 2017), advertisements (Slater, Oliver, \& Appel, 2019), narratives in texts and television (Freeman et al., 2009) and Facebook posts (Dale et al., 2020). The elevating stimuli can facilitate helping behaviour (Freeman et al., 2009; Schnall et al., 2010; Van de Vyver \& Abrams, 2015), reduce prejudice (Krämer et al., 2017; Lai, Haidt, \& Nosek, 2014; Oliver et al., 2015), and increase proenvironmental behaviour intentions (Moreton, Arena, Hornsey, Crimston, \& Tiliopoulos, 2019).

\subsection{Awe}

Awe refers to "emotional experiences that involve vastness and accommodation...in response to a charismatic leader, a grand vista, or symphony" (Keltner \& Haidt, 2003, p. 304). More specific forms of awe such as aesthetic awe (i.e., the emotional reaction to beauty, Konečni, 2005) and awe in nature (Anderson, Monroy, \& Keltner, 2018) have been proposed as well. Hence, awe is typically defined by its feeling component (i.e., feelings of vastness), its cognitive component (i.e., building new schemas based on one's experience) and its eliciting situation (i.e., power or beauty depending on the type of awe). Characteristic items are 'wonder,' 'inspiration,' 'moved,' and 'awe' (Stellar et al., 2017). Awe can be induced through presentations of nature in videos (Piff, Dietze, Feinberg, Stancato, \& Keltner, 2015) or virtual reality (Chirico et al., 2017) or through specific types of music (Pilgrim, Norris, \& Hackathorn, 2017). Episodes of awe are associated with perceiving the self as small (Shiota, Keltner, \& Mossman, 2007). Stimuli that elicit awe can increase modesty (Stellar et al., 2018) and prosocial behaviour (Piff et al., 2015). Hence, although the elicitors of moral elevation and awe differ (moral virtue vs. power and beauty), they are usually assessed with similar items and exhibit similar behavioural consequences.

\subsection{Kama Muta}

Kama Muta is "the emotion evoked by sudden intensification of communal sharing," where communal sharing 
refers to relationships in which the participants feel that they are "equivalent, belong together, care for and trust each other" (Fiske, Schubert, \& Seibt, 2017, p. 2). This definition focuses exclusively on the eliciting situation (i.e., communal sharing) and includes any emotional reaction to psychological closeness among individuals. Characteristic items are 'moving,' 'touching,' and 'heartwarming' (Zickfeld et al., 2019). The intensity of kama muta is associated with perceived closeness among individuals (Schubert, Zickfeld, Seibt, \& Fiske, 2018). Kama muta is mainly studied in response to narratives in online videos (Schubert et al., 2018; Zickfeld et al., 2019) or in response to pictures and videos showing cute animals (Steinnes, Blomster, Seibt, Zickfeld, \& Fiske, 2019). Situations that elicit kama muta can contribute to humanizing out-groups (Blomster Lyshol, Thomsen, \& Seibt, 2020). These feelings and consequences of kama muta exhibit considerable overlap with the feelings and consequences of moral elevation and awe.

\subsection{Admiration}

Admiration is defined as the "emotional response to non-moral excellence" such as skill or effort (Algoe \& Haidt, 2009, p. 107). This definition again focuses on the eliciting situation (i.e., skill and effort) and includes any emotional reaction to these situations. Characteristic items for assessing admiration are 'admiration,' 'respect,' 'moved,' 'inspired,' and 'awe' (Onu, Kessler, \& Smith, 2016). Admiration can be elicited by television documentaries about star athletes (Algoe \& Haidt, 2009) or autobiographical recall tasks (Schindler, Paech, \& Löwenbrück, 2015). Although feelings of admiration overlap with the experience of moral elevation, awe, and kama muta, the consequences of admiration differ somewhat from the consequences of these other emotions. Situations that elicit admiration facilitate achievement motivation (Algoe \& Haidt, 2009), imitation (Schindler et al., 2015) and the willingness to receive learning-related help from an outgroup member (Onu, Smith, \& Kessler, 2015).

\subsection{Appreciation}

Appreciation is defined as "the perception of deeper meaning, the feeling of being moved, and the motivation to elaborate on thoughts and feelings inspired by the experience" (Oliver \& Bartsch, 2010, p. 76). This definition includes appraisals (i.e., the perception of deeper meaning), feelings (i.e., being moved), and motivation (i.e., elaboration). As this definition is not restricted to a specific eliciting situation, the concept of appreciation covers typical episodes of moral elevation (i.e., being moved by moral virtue), episodes of kama muta (i.e., being moved by closeness), as well as episodes of admiration (i.e., being moved by skill). Characteristic items for assessing appreciation are 'being touched,' 'being moved,' 'tender,' and 'poignant' (Oliver et al., 2018). Appreciation can be induced by movies (Wirth, Hofer, \&
Schramm, 2012), textual narratives (Lewis, Tamborini, \& Weber, 2014), social media (Dale et al., 2020; Ji et al., 2019; Rieger \& Klimmt, 2019), and by playing video games (Daneels et al., 2021). Episodes of appreciation are associated with reduced prejudice (Bartsch, Oliver, Nitsch, \& Scherr, 2016; Oliver et al., 2015) and with motivation for personal growth (Bartsch, Kalch, \& Oliver, 2014; Oliver \& Bartsch, 2011).

\subsection{Being Moved}

Being moved is defined as an emotional episode that is experienced as moving, with no restrictions on the eliciting conditions (Cova \& Deonna, 2014; Menninghaus et al., 2015). Characteristic items are 'being moved,' 'overwhelmed,' and 'poignant' (Landmann et al., 2019). This construct differs from the previous ones by focusing exclusively on the experiential component of the emotion. Feelings of being moved are associated with tears in one's eyes and chills (Landmann et al., 2019). Situations that are perceived as meaningful (Cova, Deonna, \& Sander, 2017) and exhibiting virtuous behaviours despite unfavourable circumstances (e.g., outstanding achievement despite a difficult childhood; Strick \& Van Soolingen, 2018) are particularly moving. Being moved can be induced by movies (Landmann et al., 2019), online videos (Landmann \& Rohmann, 2020), and textual narratives (Strick \& Van Soolingen, 2018). These moving stimuli can enhance the intention to help others, to spend more time with close others, to improve one's own achievement (Landmann et al., 2019) and to participate in collective action (Landmann \& Rohmann, 2020).

\subsection{Tenderness}

Tenderness can be defined as an affective state associated with feelings of warmth, compassion, and sympathy (Oliver, 2008). It is often assessed with the single item 'tender' (Kalawski, 2010; Lishner, Batson, \& Huss, 2011). Tenderness constitutes a prevalent reaction to movies (Schaefer, Nils, Sanchez, \& Philippot, 2010) and music (Eerola \& Vuoskoski, 2011). It is elicited by perceived vulnerability (Lishner et al., 2011) and associated with caring behaviour (López-Pérez, Carrera, Oceja, Ambrona, \& Stocks, 2019).

\subsection{Differences and Similarities between the Conceptualizations of Eudaimonic Emotions}

The feelings associated with these concepts highly overlap. For instance, feelings of inspiration and awe are part of moral elevation, admiration, and awe. Similarly, being touched is covered by both kama muta and appreciation. Furthermore, feelings of being moved are prevalent in all of these concepts. Some of the concepts can be differentiated only when additionally considering their elicitors. For instance, moral elevation is the emotional reaction to virtue, whereas kama muta is the emotional reaction 
to psychological closeness and admiration the emotional reaction to skill. In other words, some of the proposed emotions are elicited in different situations but are experienced similarly.

This problem is rooted in different approaches of defining emotions. Some eudaimonic emotions are defined by their feeling components (being moved, tenderness) whereas others are defined by their elicitors (kama muta, admiration) or by a combination of feelings and elicitors (moral elevation, awe, appreciation). Each of these approaches has its advantages and drawbacks. For instance, defining emotions by their feelings fits very well to the way emotions are measured. However, it also means to rely on their vernacular use (see Fiske, 2020, for a similar argument). By contrast, defining emotions by their elicitors does not rely on laypersons' use of emotion labels. However, it means that the elicitors are predetermined by definition and hence the conditions that elicit the emotion cannot be empirically investigated without engaging in circular reasoning (see Landmann \& Rohmann, 2020, for a similar argument).

A closer look on definitions of emotions in general and definitions of negative emotions can help to address this problem. Emotions can be defined as episodes characterized by changes in appraisals, motor expression, autonomic physiology, action tendency, and subjective feelings (Scherer, 2005). The feeling component of an emotion is not just one component among others, but can be defined as the subjective experience of the other components (Scherer, 2005). Consistent with this view, basic emotions are usually associated with specific feelings. For instance, anger is associated with feeling angry and outraged, whereas fear is associated with feeling fearful and anxious. These basic negative emotions can then be further differentiated based on their elicitors. For instance, people can experience fear of spiders (arachnophobia) or fear of heights (acrophobia).
Furthermore, they can be angry about an injustice (moral outrage), about a negative outcome for themselves (personal anger) or about a negative outcome for someone else (empathic anger; Landmann \& Hess, 2017). Hence, differentiating emotions based on their feeling components to form basic emotion categories and further differentiating these basic emotions depending on their elicitors seems to be a common-sense approach for negative emotions.

However, this principle has not yet been applied to positive emotions. Previous taxonomies of positive emotions consider only a subset of eudaimonic emotions (Shiota et al., 2017; Tong \& Jia, 2017; Weidman \& Tracy, 2020; Yih et al., 2020). To address this gap, I propose a taxonomy of eudaimonic emotions that differentiates between feeling-specific and elicitor-specific emotions. The integration of research based on this framework is then used to make predictions about the behavioural consequences of eudaimonic emotions.

\section{A Framework of Eudaimonic Emotions}

Based on the definition, measurement and empirical studies on the different positive emotions mentioned above, I propose a framework to structure the diverse existing conceptualizations of eudaimonic emotions and propose an explanation for their consequences for pro- and anti-social behaviour. This framework encompasses the following propositions, which are depicted in Table 1.

\subsection{Feeling-Specific Types of Eudaimonic Emotions}

Eudaimonic emotions that can be differentiated based on the involved feelings can be regarded as feelingspecific (see Table 1). Feelings of being moved (moved, overwhelmed, poignant) and tenderness (touched,

Table 1. A framework of eudaimonic (appreciative) emotions.

\begin{tabular}{|c|c|c|c|}
\hline \multicolumn{4}{|c|}{ Feeling-Specific Eudaimonic Emotions } \\
\hline \multicolumn{2}{|c|}{$\begin{array}{c}\text { Elevation } \\
\text { (elevated, sublime, heightened) }\end{array}$} & \multicolumn{2}{|c|}{$\begin{array}{c}\text { Awe } \\
\text { (in awe, humble, devoted) }\end{array}$} \\
\hline \multicolumn{2}{|c|}{ Appraisal: Powerful Self } & \multicolumn{2}{|c|}{ Appraisal: Small Self } \\
\hline \multicolumn{2}{|c|}{$\begin{array}{c}\text { Being Moved } \\
\text { (moved, overwhelmed, poignant) }\end{array}$} & \multicolumn{2}{|c|}{$\begin{array}{c}\text { Tenderness } \\
\text { (touched, stirred, tender) }\end{array}$} \\
\hline \multicolumn{2}{|c|}{ Appraisal: Positive Deviation from a Standard } & \multicolumn{2}{|c|}{ Appraisal: Vulnerability } \\
\hline \multicolumn{4}{|c|}{ Elicitor-specific Eudaimonic Emotions } \\
\hline Aesthetic Awe & Musical Chills & Hope & Nostalgia \\
\hline Elicitor: Beauty & Elicitor: Music & Elicitor: Positive Future & Elicitor: Positive Past \\
\hline Religious Awe & Kama Muta & Admiration & Adoration \\
\hline Elicitor: Supernatural & Elicitor: Closeness & Elicitor: Others' Achievements & Elicitor: Others' Character \\
\hline Awe in Nature & Moral Elevation & Pride & Gratitude \\
\hline Elicitor: Nature & Elicitor: Moral Virtue & Elicitor: Own Achievements & Elicitor: Receiving Help \\
\hline
\end{tabular}


stirred, tender) are typically defined by their feelings (see Section 2). This principle can be applied to feelings of elevation (elevated, sublime, and heightened) and awe (in awe, humble, and devoted) as well. First evidence suggests that these emotions can be empirically differentiated based on their feeling component (Landmann \& Hutt, 2021) and their vocalizations (Cowen, Elfenbein, Laukka, \& Keltner, 2019). Hence, they can be regarded as feeling-specific. Furthermore, research has revealed that awe is associated with perceiving the self as small (Shiota et al., 2007), whereas feeling elevated is associated with perceiving the self as big and strong (Landmann \& Hutt, 2021), being moved is associated with appraisals of surpassing standards (Landmann et al., 2019) and tenderness with perceived vulnerability (Lishner et al., 2011). Hence, these feelings seem to be associated with different appraisals.

\subsection{Elicitor-Specific Types of Eudaimonic Emotions}

A large set of eudaimonic emotions cannot be differentiated based on their feeling components. As noted above, moral elevation (i.e., being moved by virtue), aesthetic awe (i.e., being moved by beauty), admiration (i.e., being moved by skill), and kama muta (i.e., being moved by communal sharing) are defined with regard to their eliciting situations. These emotions are thus referred to as elicitor-specific emotions (see Table 1). However, the set of elicitor-specific emotions is not limited to these concepts. Related emotional concepts such as gratitude (i.e., being moved by self-benefitting help; McCullough, Kilpatrick, Emmons, \& Larson, 2001), pride (i.e., being moved by one's own behaviour; Williams \& DeSteno, 2008), adoration (i.e., being moved by someone's character; Schindler et al., 2015), hope (i.e., being moved by expectations about the future; Bruininks \& Malle, 2005), nostalgia (i.e., being moved by the past; Wildschut, Sedikides, Arndt, \& Routledge, 2006), and musical chills (i.e., being moved by music; Konečni, 2005) can be integrated into this framework as well. Although they are less frequently studied with regard to eudaimonia than the concepts outlined in Section 2, they likewise encompass eudaimonic feelings (e.g., being moved) and they can be defined by their elicitors. Indeed, any further emotion that meets these criteria could be added to the list of elicitor-specific eudaimonic emotions.

The associations between feeling-specific and the elicitor-specific emotions depend on how a person appraises the respective situation. For instance, an episode of pride will be experienced as elevating if the self is appraised as powerful. Episodes of kama muta are likely associated with tenderness, because closeness between people often goes along with perceived vulnerability. Furthermore, the elicitor-specific emotions may be experienced simultaneously. For instance, someone may be morally elevated by another's good deed and experience admiration at the same time because the behaviour is perceived as exceptional performance.
Appreciation encompasses feelings from all these feeling-specific types with no restrictions on the eliciting situations and can thus be considered the broadest concept. It may be used interchangeably with the term eudaimonic emotions. The proposed framework can be used to standardize the measurement of appreciation. To cover the full range of feelings associated with appreciation, the complete list of feeling-specific emotion items could be used (i.e., elevated, sublime, heightened, in awe, humble, devoted, moved, overwhelmed, poignant, touched, stirred, tender). This ensures coverage of the most frequently used items for eudaimonic emotions and allows for the study of subtle differences between appreciative feelings. For instance, some episodes of appreciation may be dominated by feeling elevated, whereas others may be experienced more as tenderness or awe.

Some eudaimonic emotions may be more prevalent in the media context than others. For instance, feelings of being moved are elicited by positive deviations from standards, such as exceptional helpfulness or outstanding achievements (Landmann et al., 2019). Such exceptional behaviour is rather rare in everyday life but frequently reported in films and social media (Dale et al., 2020; Ji et al., 2019; Rieger \& Klimmt, 2019). By contrast, awe in response to nature may be rare in media because these emotional episodes are facilitated by experiencing the self in nature in a way that involves all human senses (Landmann, 2020). Mimicking such situations with media is a challenging task in virtual reality studies (e.g., Chirico et al., 2017).

Moreover, the prevalence of the different eudaimonic emotions may depend on the type of media. Audiovisual media such as movies or YouTube clips can elicit musical chills, which is not possible with print media. Similarly, pride and gratitude require some sort of interaction. For instance, someone can feel proud and elevated when their contribution is published on Wikipedia, when their number of Instagram followers significantly increases, or when they win a challenging digital game. Furthermore, someone may experience deep feelings of gratitude when others step in on social media platforms to protect them from cyberbullying. Hence, pride and gratitude can be experienced in social and interactive media contexts. However, these emotions are unlikely to emerge in the context of traditional mass media such as print, radio, or film.

\subsection{Value-Specific and General Effects of Eudaimonic Emotions}

Based on the difference between feeling-specific and elicitor-specific eudaimonic emotions, different effects on behaviour can be proposed. First, the effects of eudaimonic emotions may depend on the eliciting context. Specifically, when a situation is moving, the value that elicited the emotion may be supported. This idea relies on a broad conceptualization of values as 
"trans-situational goals...that serve as guiding principles in the life of a person" (Schwartz, 2007, p. 712). Such guiding principles (or values) can be moral values like justice but also non-moral values like achievement (Schwartz, 2007). For instance, being moved by moral virtue should enhance pro-social behaviour, whereas being moved by skill should enhance behaviour directed at self-improvement. This proposition is based on Cova and Deonna's (2014) claim that feelings of being moved reorganize the emoter's values, strengthening the value that elicited the emotion. Consequently, strengthening a specific value should facilitate behaviour that is congruent with that value.

Empirical evidence concerning this question is so far mixed. In line with the value-specific effect of eudaimonic emotions, being moved by virtue can enhance prosocial motivation and behaviour (Freeman et al., 2009; Krämer et al., 2017; Schnall et al., 2010; Van de Vyver, \& Abrams, 2015) and being moved by achievements and effort can enhance achievement motivation (Baldwin \& Bente, 2021; Landmann et al., 2019). However, in opposition to the value-specific effect of eudaimonic emotions, being moved by nature and architecture can enhance pro-social behaviour (Piff et al., 2015) and being moved by moral virtue can enhance pro-environmental behavioural intentions (Moreton et al., 2019). In sum, although being moved by a specific value facilitates value-congruent behaviour, behaviours that represent different values are sometimes also positively affected.

Hence, eudaimonic emotions may generally facilitate action directed at eudaimonic goals. The consequences of being moved may be a combination of these general and value-specific effects. Specifically, moving situations may reveal strong effects on value-congruent behaviour (e.g., being moved by moral virtue facilitates helping behaviour and being moved by skill increases achievement motivation) as well as weaker effects on behaviour directed at other eudaimonic goals (e.g., being moved by moral virtue increases achievement motivation and being moved by skill increases pro-social intentions).

These processes presumably interact with individual differences as well as developmental and social influences. Media effects in general are susceptible to individual, developmental, and social factors (Valkenburg \& Peter, 2013) and individuals differ in their susceptibility to eudaimonic emotions (e.g., Hofer, Allemand, \& Martin, 2014; Oliver \& Raney, 2011; Pohling, Diessner, Stacy, Woodward, \& Strobel, 2019). However, evidence for individual differences in the effects of eudaimonic emotions is so far mixed. For instance, in three studies using audio-visual and text-based stimuli, the extent to which a person was moved by outstanding positive behaviour depended on the person's values (Landmann et al., 2019). By contrast, in a study by Pohling et al. (2019), participants' values did not influence their proneness to elevation but moderated the effect of an elevating video on cooperation in an economic game. Furthermore, experiences of eudaimonic emotions do not always affect attitudes and behaviour (Ellithorpe, Ewoldsen, \& Oliver, 2015; Landmann et al., 2019). Hence, the interactions between eudaimonic emotions and individual differences, developmental and social factors is not yet clear.

\section{Implications for the Bright and Dark Sides of Eudaimonic Emotions}

The proposed framework of eudaimonic emotions enhances our understanding of the bright side of these emotions, such as beneficial effects for pro-social behaviour, but also their dark side, such as their potential to be used to manipulate people-where "bright" refers to the moral value of enhancing others' well-being and "dark" refers to violating this value (Haidt \& Joseph, 2004). As outlined in Section 2 and Section 3, some types of eudaimonic emotions, such as moral elevation, awe, and kama muta, enhance the tendency to help others and reduce negative attitudes towards outgroups. This can be regarded as the bright side of being moved. However, feelings of being moved may also be used to manipulate people. The following considerations provide explanations for the relevance of eudaimonic emotions for the manipulative effect of propaganda.

Eudaimonic emotions may generally enhance behaviour directed at eudaimonic goals, but exert valuespecific effects in addition (see Section 3). Hence, the consequences of these emotions depend on the value that elicited the emotion. When people are moved by pro-social acts, their own pro-social behaviour is likely to be enhanced. However, when people are moved by achievement or power, behavioural consequences likely concern achievement and powerful behaviour. These effects may contribute to the relevance of being moved for radicalization. Propaganda presents a variety of different values, such as human connection, overcoming obstacles, and beauty (Frischlich, 2020). The presentation of these values in an exceptionally positive way can elicit feelings of being moved and thus strengthen behaviour that supports the respective value. Action appeals communicated by extremists arguably match their respective values. For instance, the duty to take care of supposedly vulnerable group members like women and children is a prominent theme in Islamist and right-wing extremist propaganda (Frischlich et al., 2018). The presentation of these values of duty and care can be moving, and hence motivate people follow the call for action that is often associated with the moving material. This may explain why moving propaganda material is so effective.

Furthermore, eudaimonic emotions are associated with the experience of meaningfulness (see Section 2). This may enhance the impression that the ideals behind the eliciting situation must be true and valuable. In line with this claim, Cova et al. (2017) found that being moved by pseudo-profound statements predicts to what extent someone agrees with these statements and nostalgic 
themes in right-wing propaganda can increase its persuasiveness (Menke \& Wulf, 2021). Furthermore, moving media can buffer against death anxiety (Rieger et al., 2015), presumably because feeling moved goes along with the perception of meaningfulness, which is usually threatened when people think about their own death. Thus, a specific value in propaganda material may be moving and induce an impression of meaningfulness, which in turn spreads to the propaganda message and eventually even to the source of this message.

\section{Limitations and Future Research}

The framework proposes differentiating between feelingspecific and elicitor-specific eudaimonic emotions thus allowing for an integration of previous research on specific eudaimonic emotions such as moral elevation, awe and admiration. Some emotions like aesthetic awe, religious awe, awe in nature, moral elevation, kama muta, and musical chills are defined by their elicitors and cannot be differentiated by their feeling components. Hence, considering them as elicitor-specific rather than feeling-specific is indisputable. However, the classification of hope, nostalgia, admiration, adoration, gratitude, and pride as elicitor-specific is not that clear. Future research can reveal whether they should rather be considered as feeling-specific. Furthermore, associations within the feeling-specific emotions as well as within the elicitor-specific emotions are still unclear. It is possible that some feeling-specific eudaimonic emotions (e.g., tenderness and being moved) occur together more frequently than others (e.g., elevation and awe) thus indicating a structure within the feeling-specific emotions. The same holds for associations between elicitor-specific emotions. Future research should investigate the associations between these emotions to further advance the framework.

Although the proposed framework is consistent with previous findings, it has not yet been systematically tested. For instance, the claim that eudaimonic emotions have a general effect on behaviour directed at eudaimonic goals as well as a value-specific effect on valuecongruent behaviour is consistent with previous findings on eudaimonic responses to moral virtue and achievement (see Section 3.3). Future research should test the claim for other values such as courage or duty.

The extant evidence shows that eudaimonic emotions can be elicited by extremist propaganda and that the intensity of these feelings are associated with the persuasiveness of the material (Frischlich, 2020; Frischlich et al., 2018). The proposed framework suggests causal processes that explain these findings. Investigating these causal links in the context of radicalization is a challenging task for future research.

Furthermore, interventions should be developed to reduce the manipulative power of eudaimonic emotions. The theoretical considerations outlined above as well as existing empirical findings suggest that eudaimonic emo- tions increase the persuasiveness of messages and ultimately even agreement with the ideology behind the message. Hence, informing the public about the processes that can be elicited by eudaimonic feelings may decrease the manipulating effect of propaganda.

\section{Conclusions}

The proposed framework suggests a differentiation between feeling-specific and elicitor-specific eudaimonic emotions as well as their general and value-specific effects on behaviour. Structuring eudaimonic emotions along these lines helps to explain their bright side (e.g., facilitating effects on pro-social behaviour) as well as their dark side (e.g., their manipulative role in propaganda). The framework provides a foundation for combining different lines of research from psychology, philosophy, as well as media and communication studies, thus facilitating transfer of knowledge among these disciplines. The framework can help to select items for assessing appreciation, being moved, tenderness, awe, and elevation. Furthermore, it provides a basis for more rigorously testing causal effects of eudaimonic emotions in response to media in the context of radicalization as well as for developing interventions to reduce the manipulative power of these feelings.

\section{Acknowledgments}

I want to thank Florian Cova and Verena Schneider for comments on an earlier draft of this article.

\section{Conflict of Interests}

The author declares no conflict of interests.

\section{References}

Algoe, S. B., \& Haidt, J. (2009). Witnessing excellence in action: The 'other-praising' emotions of elevation, gratitude, and admiration. The Journal of Positive Psychology, 4(2), 105-127. https://doi.org/10.1080/ 17439760802650519

Anderson, C. L., Monroy, M., \& Keltner, D. (2018). Awe in nature heals: Evidence from military veterans, at-risk youth, and college students. Emotion, 18(8), 1195-1202. https://doi.org/10.1037/emo0000442

Baldwin, J., \& Bente, G. (2021). The winner doesn't take it all: Analyzing audience responses to an inspirational sports narrative. Media and Communication, 9(2), 202-214. https://doi.org/10.17645/mac.v9i2.3840

Bartsch, A., Kalch, A., \& Oliver, M. B. (2014). Moved to think: The role of emotional media experiences in stimulating reflective thoughts. Journal of Media Psychology: Theories, Methods, and Applications, 26(3), 125-140. https://doi.org/10.1027/1864$1105 / a 000118$

Bartsch, A., Oliver, M. B., Nitsch, C., \& Scherr, S. (2016). 
Inspired by the Paralympics: Effects of empathy on audience Interest in para-sports and on the destigmatization of persons with disabilities. Communication Research, 45(4), 525-553. https://doi.org/10.1177\% 2F0093650215626984

Blomster Lyshol, J. K., Thomsen, L., \& Seibt, B. (2020). Moved by observing the love of others: Kama muta evoked through media fosters humanization of outgroups. Frontiers in Psychology, 11. https://doi.org/ 10.3389/fpsyg.2020.01240

Bruininks, P., \& Malle, B. F. (2005). Distinguishing hope from optimism and related affective states. Motivation \& Emotion, 29(4), 324-352. https://doi.org/ 10.1007/s11031-006-9010-4

Chirico, A., Cipresso, P., Yaden, D. B., Biassoni, F., Riva, G., \& Gaggioli, A. (2017). Effectiveness of immersive videos in inducing awe: an experimental study. Scientific Reports, 7(1), 1-11. https://doi.org/10.1038/ s41598-017-01242-0

Cova, F., \& Deonna, J. A. (2014). Being moved. Philosophical Studies, 169(3), 447-466. https://doi.org/ 10.1007/s11098-013-0192-9

Cova, F., Deonna, J. A., \& Sander, D. (2017). "That's deep!": The role of being moved and feelings of profundity in the appreciation of serious narratives. In D. R. Wehrs \& T. Blake (Eds.), The Palgrave handbook of affect studies and textual criticism (pp. 347-369). Cham: Palgrave Macmillan.

Cowen, A. S., Elfenbein, H. A., Laukka, P., \& Keltner, D. (2019). Mapping 24 emotions conveyed by brief human vocalization. American Psychologist, 74(6), 698-712. https://doi.org/10.1037/amp0000399

Dale, K. R., Raney, A. A., Janicke, S. H., Sanders, M. S., \& Oliver, M. B. (2017). YouTube for good: A content analysis and examination of elicitors of self-transcendent media. Journal of Communication, 67(6), 897-919. https://doi.org/10.1111/jcom. 12333

Dale, K. R., Raney, A. A., Ji, Q., Janicke-Bowles, S. H., Baldwin, J., Rowlett, J. T., . . . Oliver, M. B. (2020). Selftranscendent emotions and social media: Exploring the content and consumers of inspirational Facebook posts. New Media \& Society, 22(3), 507-527. https:// doi.org/10.1177\%2F1461444819865720

Daneels, R., Bowman, N. D., Possler, D., \& Mekler, E. D. (2021). The 'eudaimonic experience': A scoping review of the concept in digital games research. Media and Communication, 9(2), 178-190. https:// doi.org/10.17645/mac.v9i2.3824

Eerola, T., \& Vuoskoski, J. K. (2011). A comparison of the discrete and dimensional models of emotion in music. Psychology of Music, 39(1), 18-49. https:// doi.org/10.1177\%2F0305735610362821

Ellithorpe, M. E., Ewoldsen, D. R., \& Oliver, M. B. (2015). Elevation (sometimes) increases altruism: Choice and number of outcomes in elevating media effects. Psychology of Popular Media Culture, 4(3), 236-250. https://doi.org/10.1037/ppm0000023
Fiske, A. P. (2020). The lexical fallacy in emotion research: Mistaking vernacular words for psychological entities. Psychological Review, 127(1), 95-113. https:// doi.org/10.1037/rev0000174

Fiske, A. P., Schubert, T. W., \& Seibt, B. (2017). The bestloved story of all time: Overcoming all obstacles to be reunited, evoking kama muta. Evolutionary Studies in Imaginative Culture, 1(1), 67-70. https://www.jstor. org/stable/10.26613/esic.1.1.12

Freeman, D., Aquino, K., \& McFerran, B. (2009). Overcoming beneficiary race as an impediment to charitable donations: Social dominance orientation, the experience of moral elevation, and donation behaviour. Personality and Social Psychology Bulletin, 35(1), 72-84. https://doi.org/10.1177\% 2F0146167208325415

Frischlich, L. (2020). \#Dark inspiration: Eudaimonic entertainment in extremist Instagram posts. New Media \& Society, 23(3), 554-577. https://doi.org/10.1177/ 1461444819899625

Frischlich, L., Rieger, D., Morten, A., \& Bente, G. (2018). The power of a good story: Narrative persuasion in extremist propaganda and videos against violent extremism. International Journal of Conflict and Violence, 12, 1-16. https://doi.org/10.4119/UNIBI/ijcv. 644

Haidt, J. (2000). The positive emotion of elevation. Prevention \& Treatment, 3(1). https://doi.org/10.1037/ 1522-3736.3.1.33c

Haidt, J., \& Joseph, C. (2004). Intuitive ethics: How innately prepared intuitions generate culturally variable virtues. Daedalus, 133(4), 55-66. https://doi.org/ 10.1162/0011526042365555

Hofer, M., Allemand, M., \& Martin, M. (2014). Age differences in nonhedonic entertainment experiences. Journal of Communication, 64(1), 61-81. https://doi. org/10.1111/jcom.12074

Ji, Q., Raney, A. A., Janicke-Bowles, S. H., Dale, K. R., Oliver, M. B., Reed, A., . . Raney, A. A. (2019). Spreading the good news: Analyzing socially shared inspirational news content. Journalism \& Mass Communication Quarterly, 96(3), 872-893. https://doi.org/ $10.1177 \% 2 F 1077699018813096$

Kalawski, J. P. (2010). Is tenderness a basic emotion? Motivation and Emotion, 34(2), 158-167. https://doi. org/10.1007/s11031-010-9164-y

Keltner, D., \& Haidt, J. (2003). Approaching awe, a moral, spiritual, and aesthetic emotion. Cognition and Emotion, 17(2), 297-314. https://doi.org/ 10.1080/02699930302297

Konečni, V. J. (2005). The aesthetic trinity: Awe, being moved, thrills. Bulletin of Psychology and the Arts, 5(2), 27-44. https://psycnet.apa.org/doi/10.1037/ e674862010-005

Krämer, N., Eimler, S. C., Neubaum, G., Winter, S., Rösner, L., \& Oliver, M. B. (2017). Broadcasting one world: How watching online videos can elicit elevation and reduce stereotypes. New Media \& 
Society, 19(9), 1349-1368. https://doi.org/10.1177\% 2F1461444816639963

Lai, C. K., Haidt, J., \& Nosek, B. A. (2014). Moral elevation reduces prejudice against gay men. Cognition and Emotion, 28(5), 781-794. https://doi.org/10.1080/ 02699931.2013 .861342

Landmann, H. (2020). Emotions in the context of environmental protection: Theoretical considerations concerning emotion types, eliciting processes, and affect generalization. Umweltpsychologie, 24(2), 61-73. http://umps.de/php/artikeldetails.php?id=745

Landmann, H., Cova, F., \& Hess, U. (2019). Being moved by meaningfulness: Appraisals of surpassing internal standards elicit being moved by relationships and achievements. Cognition and Emotion, 33(7), 1387-1409. https://doi.org/10.1080/ 02699931.2019 .1567463

Landmann, H., \& Hess, U. (2017). What elicits thirdparty anger? The effects of moral violation and others' outcome on anger and compassion. Cognition and Emotion, 31(6), 1097-1111. https://doi.org/ 10.1080/02699931.2016.1194258

Landmann, H., \& Hutt, N. (2021). The structure of eudaimonic emotions: Differences and similarities between being moved, elevation, awe and tenderness. Manuscript in preparation.

Landmann, H., \& Rohmann, A. (2020). Being moved by protest: Group-efficacy beliefs and injustice appraisals affect community-oriented and punishment-oriented collective action for forest protection via positive and negative emotions. Journal of Environmental Psychology, 71. https://doi.org/ 10.1016/j.jenvp.2020.101491

Lewis, R. J., Tamborini, R., \& Weber, R. (2014). Testing a dual-process model of media enjoyment and appreciation. Journal of Communication, 64(3), 397-416. https://doi.org/10.1111/jcom.12101

Lishner, D. A., Batson, C. D., \& Huss, E. (2011). Tenderness and sympathy: Distinct empathic emotions elicited by different forms of need. Personality and Social Psychology Bulletin, 37(5), 614-625. https://doi.org/ 10.1177\%2F0146167211403157

López-Pérez, B., Carrera, P., Oceja, L., Ambrona, T., \& Stocks, E. (2019). Sympathy and tenderness as components of dispositional empathic concern: Predicting helping and caring behaviours. Current Psychology, 38(2), 458-468. https://doi.org/10.1007/s12144017-9615-7

McCullough, M. E., Kilpatrick, S. D., Emmons, R. A., \& Larson, D. B. (2001). Is gratitude a moral affect? Psychological Bulletin, 127(2), 249-266. https://doi.org/ 10.1037/0033-2909.127.2.249

Menke, M., \& Wulf, T. (2021). The dark side of inspirational pasts: An investigation of nostalgia in rightwing populist communication. Media and Communication, 9(2), 237-249. https://doi.org/10.17645/ mac.v9i2.3803

Menninghaus, W., Wagner, V., Hanich, J., Wassiliwizky,
E., Kuehnast, M., \& Jacobsen, T. (2015). Towards a psychological construct of being moved. PLOS ONE, 10(6). https://doi.org/10.1371/journal.pone. 0128451

Moreton, S. G., Arena, A., Hornsey, M. J., Crimston, C. R., \& Tiliopoulos, N. (2019). Elevating nature: Moral elevation increases feelings of connectedness to nature. Journal of Environmental Psychology, 65. https://doi. org/10.1016/j.jenvp.2019.101332

Oliver, M. B. (2008). Tender affective states as predictors of entertainment preference. Journal of Communication, 58(1), 40-61. https://doi.org/10.1111/ j.1460-2466.2007.00373.x

Oliver, M. B., \& Bartsch, A. (2010). Appreciation as audience response: Exploring entertainment gratifications beyond hedonism. Human Communication Research, 36(1), 53-81. https://doi.org/10.1111/ j.1468-2958.2009.01368.x

Oliver, M. B., \& Bartsch, A. (2011). Appreciation of entertainment: The importance of meaningfulness via virtue and wisdom. Journal of Media Psychology, 23(1), 29-33. https://doi.org/10.1027/1864-1105/ a000029

Oliver, M. B., Hartmann, T., \& Woolley, J. K. (2012). Elevation in response to entertainment portrayals of moral virtue. Human Communication Research, 38, 360-378. https://doi.org/10.1111/j.1468-2958. 2012.01427.x

Oliver, M. B., Kim, K., Hoewe, J., Chung, M. Y., Ash, E., Woolley, J. K., \& Shade, D. D. (2015). Media-induced elevation as a means of enhancing feelings of intergroup connectedness. Journal of Social Issues, 71(1), 106-122. https://doi.org/10.1111/josi.12099

Oliver, M. B., \& Raney, A. A. (2011). Entertainment as pleasurable and meaningful: Identifying hedonic and eudaimonic motivations for entertainment consumption. Journal of Communication, 61(5), 984-1004. https://doi.org/10.1111/j.1460-2466.2011.01585.x

Oliver, M. B., Raney, A. A., Slater, M. D., Appel, M., Hartmann, T., Bartsch, A., . . . Vorderer, P. (2018). Selftranscendent media experiences: Taking meaningful media to a higher level. Journal of Communication, 68(2), 380-389. https://doi.org/10.1093/joc/jqx020

Onu, D., Kessler, T., \& Smith, J. R. (2016). Admiration: A conceptual review. Emotion Review, 8(3), 218-230. https://doi.org/10.1177\%2F1754073915610438

Onu, D., Smith, J. R., \& Kessler, T. (2015). Intergroup emulation: An improvement strategy for lower status groups. Group Processes \& Intergroup Relations, 18(2), 210-224. https://doi.org/10.1177\% 2F1368430214556698

Piff, P. K., Dietze, P., Feinberg, M., Stancato, D. M., \& Keltner, D. (2015). Awe, the small self, and prosocial behaviour. Journal of Personality and Social Psychology, 108(6), 883-899. https://doi.org/10.1037/ pspi0000018

Pilgrim, L., Norris, J. I., \& Hackathorn, J. (2017). Music is awesome: Influences of emotion, personality, and 
preference on experienced awe. Journal of Consumer Behaviour, 16(5), 442-451. https://doi.org/10.1002/ cb.1645

Pohling, R., Diessner, R., Stacy, S., Woodward, D., \& Strobel, A. (2019). Moral elevation and economic games: The moderating role of personality. Frontiers in Psychology, 10. https://doi.org/10.3389/fpsyg.2019. 01381

Rieger, D., Frischlich, L., Högden, F., Kauf, R., Schramm, K., \& Tappe, E. (2015). Appreciation in the face of death: Meaningful films buffer against death-related anxiety. Journal of Communication, 65(2), 351-372. https://doi.org/10.1111/jcom.12152

Rieger, D., \& Klimmt, C. (2019). The daily dose of digital inspiration: A multi-method exploration of meaningful communication in social media. New Media \& Society, 21(1), 97-118. https://doi.org/10.1177\% 2F1461444818788323

Schaefer, A., Nils, F., Sanchez, X., \& Philippot, P. (2010). Assessing the effectiveness of a large database of emotion-eliciting films: A new tool for emotion researchers. Cognition and Emotion, 24(7), 1153-1172. https://doi.org/10.1080/02699930903 274322

Scherer, K. R. (2005). What are emotions? And how can they be measured? Social Science Information, 44(4), 695-729. https://doi.org/10.1177\% 2F0539018405058216

Schindler, I., Paech, J., \& Löwenbrück, F. (2015). Linking admiration and adoration to self-expansion: Different ways to enhance one's potential. Cognition and Emotion, 29(2), 292-310. https://doi.org/10.1080/ 02699931.2014 .903230

Schnall, S., Roper, J., \& Fessler, D. M. (2010). Elevation leads to altruistic behaviour. Psychological Science, 21(3), 315-320. https://doi.org/10.1177\% 2F0956797609359882

Schubert, T. W., Zickfeld, J. H., Seibt, B., \& Fiske, A. P. (2018). Moment-to-moment changes in feeling moved match changes in closeness, tears, goosebumps, and warmth: Time series analyses. Cognition and Emotion, 32(1), 174-184. https://doi.org/ 10.1080/02699931.2016.1268998

Schwartz, S. H. (2007). Universalism values and the inclusiveness of our moral universe. Journal of CrossCultural Psychology, 38(6), 711-728. https://doi.org/ 10.1177/0022022107308992

Shiota, M. N., Campos, B., Oveis, C., Hertenstein, M. J., Simon-Thomas, E., \& Keltner, D. (2017). Beyond happiness: Building a science of discrete positive emotions. American Psychologist, 72(7), 617-643. https://doi.org/10.1037/a0040456

Shiota, M. N., Keltner, D., \& Mossman, A. (2007). The nature of awe: Elicitors, appraisals, and effects on self-concept. Cognition and Emotion, 21(5), 944-963. https://doi.org/10.1080/02699930600923668

Slater, M. D., Oliver, M. B., \& Appel, M. (2019). Poignancy and mediated wisdom of experience: Narrative impacts on willingness to accept delayed rewards. Communication Research, 46(3), 333-354. https:// doi.org/10.1177/0093650215623838

Steinnes, K. K., Blomster, J. K., Seibt, B., Zickfeld, J. H., \& Fiske, A. P. (2019). Too cute for words: Cuteness evokes the heartwarming emotion of kama muta. Frontiers in Psychology, 10. https://doi.org/10.3389/ fpsyg.2019.00387

Stellar, J. E., Gordon, A., Anderson, C. L., Piff, P. K., McNeil, G. D., \& Keltner, D. (2018). Awe and humility. Journal of Personality and Social Psychology, 114(2), 258-269. https://doi.org/10.1037/pspi0000109

Stellar, J. E., Gordon, A. M., Piff, P. K., Cordaro, D., Anderson, C. L., Bai, Y., . . . Keltner, D. (2017). Selftranscendent emotions and their social functions: Compassion, gratitude, and awe bind us to others through prosociality. Emotion Review, 9(3), 200-207. https://doi.org/10.1177\%2F1754073916684557

Strick, M., \& Van Soolingen, J. (2018). Against the odds: Human values arising in unfavourable circumstances elicit the feeling of being moved. Cognition and Emotion, 32(6), 1231-1246. https://doi.org/ 10.1080/02699931.2017.1395729

Thomson, A. L., \& Siegel, J. T. (2017). Elevation: A review of scholarship on a moral and other-praising emotion. The Journal of Positive Psychology, 12(6), 628-638. https://doi.org/10.1080/17439760.2016.1269184

Tong, E. M. W., \& Jia, L. (2017). Positive emotion, appraisal, and the role of appraisal overlap in positive emotion co-occurrence. Emotion, 17(1), 40-54. https://doi.org/10.1037/emo0000203

Valkenburg, P. M., \& Peter, J. (2013). The differential susceptibility to media effects model. Journal of Communication, 63(2), 221-243. https://doi.org/10.1111/ jcom.12024

Van de Vyver, J., \& Abrams, D. (2015). Testing the prosocial effectiveness of the prototypical moral emotions: Elevation increases benevolent behaviours and outrage increases justice behaviours. Journal of Experimental Social Psychology, 58, 23-33. https://doi.org/ 10.1016/j.jesp.2014.12.005

Waddell, T. F., Bailey, E., \& Davis, S. E. (2017). Does elevation reduce viewers' enjoyment of media violence? Journal of Media Psychology, 31(2), 103-109. https://doi.org/10.1027/1864-1105/a000214

Weidman, A. C., \& Tracy, J. L. (2020). A provisional taxonomy of subjectively experienced positive emotions. Affective Science, 1, 1-30. https://doi.org/10.1007/ s42761-020-00009-7

Wildschut, T., Sedikides, C., Arndt, J., \& Routledge, C. (2006). Nostalgia: Content, triggers, functions. Journal of Personality and Social Psychology, 91(5), 975-993. https://doi.org/10.1037/0022-3514.91.5. 975

Williams, L. A., \& DeSteno, D. (2008). Pride and perseverance: The motivational role of pride. Journal of Personality and Social Psychology, 94(6), 1007-1017. https://doi.org/10.1037/0022-3514.94.6.1007 
Wirth, W., Hofer, M., \& Schramm, H. (2012). Beyond pleasure: Exploring the eudaimonic entertainment experience. Human Communication Research, 38(4), 406-428. https://doi.org/10.1111/j.1468-2958. 2012.01434.x

Yih, J., Kirby, L. D., \& Smith, C. A. (2020). Profiles of appraisal, motivation, and coping for positive emotions. Cognition and Emotion, 34(3), 481-497. https://doi.org/10.1080/02699931.2019.1646212

Zickfeld, J. H., Schubert, T. W., Seibt, B., Blomster, J. K., Arriaga, P., Basabe, N., ... Ding, Y. (2019). Kama muta: Conceptualizing and measuring the experience often labelled being moved across 19 nations and 15 languages. Emotion, 19(3), 402-424. https://doi.org/ 10.1037/emo0000450

\section{About the Author}

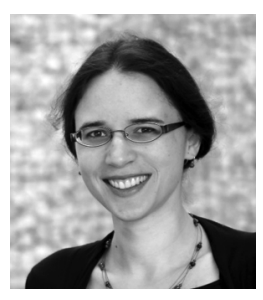

Helen Landmann (PhD) is a Post-Doctoral Researcher and Lecturer at the department of Psychology at the FernUniversität in Hagen. Her research focuses on the role of emotions for social life in the contexts of environmental protection, radicalization, and refugee integration. She employs qualitative and quantitative methods as well as experiments and field studies and promotes transfer between research and practice. 